\title{
A Review on the nucleation mechanisms of IAF nucleated on different inclusions
}

\author{
Amer Amer ${ }^{1}$ and Ahmed Shash ${ }^{2}$ \\ ${ }^{1}$ Beni Suef University Faculty of Engineering \\ ${ }^{2}$ Affiliation not available
}

May 5, 2020

\begin{abstract}
The recent trend to upgrade the mechanical properties of the low alloy structure steel is to generate the well known acicular ferrite morphology by addition of special alloying element as Micro-alloying to affect nano-size substructure. It was agreed that the key point for developing the oxide metallurgy technology is to continuously explore the potential oxides which can induce ferrite formation. Moreover, much attention had been paid to study the nucleation mechanisms of IAF nucleated on different inclusions. However, the IAF nucleation mechanisms are poorly understood. The intention of the present work is to help to a deeper understanding of the mechanism of acicular ferrite nucleation in some microallyed steel such as $\mathrm{Ti}$, Al, and Mg-microalloyed steel, which were investigated by the Author and others, aimed to optimize strength and toughness of the structure steel based on the mechanism of acicular ferrite formation.
\end{abstract}

\section{Hosted file}

200130_Review article aicular ferrite, Initial draft to Prof. A Shash.doc available at https://authorea.com/users/296122/articles/424981-a-review-on-the-nucleation-mechanismsof-iaf-nucleated-on-different-inclusions 